\title{
TOBIAS BARRETO DE MENEZES E A EDUCAÇÃO PARA UM BRASIL MODERNO (SÉCULO XIX)1
}

\author{
DOI: http://dx.doi.org/10.1590/2236-3459/71344 \\ Raylane Andreza Dias Navarro Barreto \\ Universidade Tiradentes (Unit), Brasil \\ $\cos 8$
}

\begin{abstract}
Resumo
No campo da História da Educação que vem se consolidando e que tem por objeto os intelectuais, vários são os autores que intentam desvelar seus meandros como que dando corpo a ele, incluindo um viés metodológico. Busco neste estudo destacar ideias, propostas e práticas de Tobias Barreto de Menezes, um dos autores expoentes do oitocentos brasileiro, assim como entender as questões educacionais do período, em especial no nordeste brasileiro. Nesse sentido, a análise empreendida busca articular as principais expressões desse autor em prol da educação superior feminina e da educação para o trabalho com vistas a um Brasil moderno.

Palavras-chave: educação brasileira, educação superior feminina, educação para o trabalho, história intelectual, Tobias Barreto de Menezes, século XIX.
\end{abstract}

\section{TOBIAS BARRETO DE MENEZES AND EDUCATION FOR A MODERN BRAZIL (CENTURY XIX)}

\begin{abstract}
In the field of the History of Education, which has been consolidating, and which has the intellectuals as objects, several of them are authors that attempt to unveil their meanders giving them body, including a methodological bias. I aim in this study to highlight ideas, propositions and practices of Tobias Barreto de Menezes, one of the exponent authors from the Brazil's eight hundred, as well as to understand the educational questions of that period, specially in the Northeast of Brazil. In this meaning, the undertaken analysis aims to articulate the main expressions of this author in favor of female higher education and of the education for work with a view to a modern Brazil.

Keywords: Brazilian education, women's higher education, education for work, history of intellectuals, Tobias Barreto de Menezes, nineteenth century.
\end{abstract}

\section{TOBIAS BARRETO DE MENEZES Y LA EDUCACIÓN PARA UN BRASIL MODERNO (SIGLO XIX)}

\section{Resumen}

En el campo de la Historia de la Educación que se viene consolidando y que tiene a los intelectuales como objeto, son varios los autores que intentan desvelar sus recovecos como para dar cuerpo al mismo, incluyendo un sesgo metodológico. En el presente estudio aspiro a destacar las ideas, propuestas y prácticas de Tobias

${ }^{1}$ Este artigo resulta de discussões empreendidas durante sessão coordenada no XI Congresso Lusobrasileiro de História da Educação em 2016 na cidade do Porto/Portugal. Contou com recursos do edital de Apoio a Projetos de Pesquisa - MCTI/CNPq/Universal14/2014. 
Barreto de Menezes, uno de los autores clave del siglo XIX en Brasil, así como a entender las cuestiones educativas del período, en especial en el noreste brasileño. En ese sentido, el análisis emprendido tiene como objeto articular las principales expresiones de dicho autor en pro de la educación superior femenina y de la educación para el trabajo con vistas a la modernización de Brasil.

Palabras clave: educación brasileña, educación superior femenina, educación para el trabajo, historia intelectual, Tobias Barreto de Menezes, siglo XIX.

\section{TOBIAS BARRETO DE MENEZES ET DE L'ÉDUCATION POUR UN MODERNE BRÉSIL (SIÈCLE XIX)}

\section{Résumé}

Dans le domaine de l'Histoire de l'Éducation qui est en cours de consolidation et qui vise les intellectuels, un certain nombre d'auteurs qui ont l'intention de dévoiler ses subtilités, pour donner corps à elle, y compris un biais méthodologique. II est mon but dans cette article de souligner des idées, propositions et pratiques de Tobias Barreto de Menezes, un réconnu auteur brésilien au dix-huitième siècle, ainsi que de comprendre les enjeux éducatifs de la période, en particulier dans le nord-est du Brésil. En ce sens, l'analyse effectuée cherche à articuler ses principales expressions de l'auteur en faveur de l'enseignement supérieur des femmes et de l'éducation pour le travail en vue d'un Brésil moderne.

Mots-clés: education, enseignement supérieur feminine, éducation pour le travail, histoire intellectuelle, Tobias Barreto de Menezes, XIXe Siècle. 


\section{Introdução}

$\mathrm{N}$ o cenário político e intelectual do final do século XIX brasileiro, vários foram os sujeitos autores que se destacaram por suas críticas políticas e sociais.

Fosse na tribuna, em artigos de jornais ou em livros, temas que envolviam justiça, liberdade, verdade, razão, dentre outros, foram trazidos aos debates e estampados nos escritos oitocentistas. Na seara desses escritores brasileiros estão, dentre outros, Rui Barbosa, Joaquim Nabuco e Sylvio Romero. A tais nomes se somam outros que, além de serem escritores, também se envolveram com a política, ratificando o prenunciado por Max Weber (1985) em Ciência e política: duas vocações no qual afirma que o homem que vive da política não pode ser o mesmo que vive para a política. Há, de acordo com Weber, um impedimento que faz com que a sintonia não saia a contento, isto porque o cientista se compromete com os fatos enquanto o político nem sempre pode se dedicar às causas e sim as consequências deles.

Nesse sentido, muitos são os exemplos que podem ser recolhidos ao longo da história, inclusive da brasileira, e que revelam homens que, ao assumirem algum tipo de poder político, deixaram de lado as suas descobertas como homens de ciência, da mesma forma que homens de política, uma vez conhecendo as descobertas científicas, a conceberam como uma instância distinta daquela onde se busca amparo quando se quer implantar novas ideias. Isso porque, como afirma Angela Alonso (2002), no campo político, muito mais do que as perspectivas teóricas ou doutrinárias, o que está em jogo é a eficácia da ação e o que os "acordos" devem atar em prol da consecução de uma ideia.

Goethe (2002), ao escrever a sua versão do mito de "Fausto", dá um bom exemplo disso, quando mostra um Fausto científico que dá lugar a um homem do mundo e que depois se transforma em um ateu "praticante", que faz pacto com o demônio, o que culmina ser ele um grande dono de terras e "gestor" público. A história de Fausto termina com ele e a "inquietude" dialogando sobre suas ações e suas angústias e o que delas decorrem. $\mathrm{Na}$ vida real, esse diálogo pode até ser feito, mas pouco divulgado, uma vez que os afazeres políticos não dão margem à publicização das angústias individuais. Se por um lado são poucos os homens públicos que têm essa verve, por outro, é ao homem de ciência, ao técnico do saber humano, na concepção de Bobbio (1997), que cabe o dever de não somente pensar, mas de criticar e, por vezes propor soluções para os problemas candentes, o que, por sua vez, vai de encontro à linha de análise proposta por Julien Benda (apud BOBBIO, 1997), de que o intelectual é o produtor de conhecimento e não se envolve com política. Para Bobbio (1997) os intelectuais se envolvem com a política e tomam partido, mesmo que se considere que a eficácia das ideias propostas não seja, em último caso, um problema genuinamente deles.

Nos estudos que têm por objeto os intelectuais, vários são os pesquisadores que intentam desvelar as sociabilidades e as ações destes sujeitos, buscando estabelecer um campo de estudos, incluindo-se aí a dimensão metodológica das investigações. Nesse sentido, uma das tarefas desses estudos é entender o Brasil sob a perspectiva dos intelectuais e mais precisamente desses dedicados ao campo da educação. Busca-se revelar não apenas o Brasil pensado, projetado, mas, sobretudo, as motivações, as necessidades, os pontos nevrálgicos que fizeram com que determinados problemas fossem evocados, analisados e, em alguns casos, enfrentados.

No campo da educação, em especial, um dos problemas enfrentados é aquele que 
se refere ao entendimento de nossas muitas transições. Uma forma de compreendê-las é considerar que, seja no modelo de educação seguido, nos métodos de ensino ou nos distintos programas e currículos e suas articulações com os níveis de ensino e as propostas pedagógicas, a educação brasileira conta com personagens que a impulsionaram, fosse gestando planos e reformas que, em muitos casos, foram colocadas em prática; fosse pondo em evidência os problemas existentes a partir da crítica social. Por isso, considerar o contexto histórico, as circunstâncias pessoais, as motivações, as ideias e os projetos que os identificam é contribuir com a história do intelectual e com o que esta pode legar à história da educação. Afinal, "uma vez que a atividade do intelectual (ideia, opinião, crítica, ação, projeto, erudição) é entendida como campo e objeto, a história do intelectual é também uma história das ideias, das mentalidades antropológica e sociológica." (MAGALHÃES; BARRETO, 2015, p. 66-67).

Nesse sentido, como forma de contribuir com a história da educação no Brasil, o que propus foi, por meio das ideias, propostas e práticas de Tobias Barreto (1839-1889), um dos autores expoentes do oitocentos brasileiro, entender as questões sociais do período que o motivaram a pensar a educação e qual solução encontrou/propôs. Tobias Barreto foi um mulato sergipano, autor de vários artigos e livros, além de idealizador e "criador" de jornais. Foi também professor e mentor de uma escola filosófica, denominada posteriormente de "Escola de Recife", dentro da Faculdade de Direto, na província de Pernambuco, da qual foi aluno e depois professor, entre 1882 e 1889 . Tais ações o fizeram constar na hierarquia intelectual brasileira, mas a recepção negativa de suas ideias pelos seus contemporâneos deixou a sua figura senão incógnita, indistinta para as gerações posteriores no que tange ao estrado da educação, diferentemente do campo jurídico em que seus escritos ecoam até os dias de hoje, principalmente os concernentes ao Direito Penal.

\section{Tobias e a educação}

No último quartel do século XIX, em plena efervescência política, social e pedagógica marcada pelos debates sobre a liberdade (Lei do Ventre, a Lei dos Sexagenários, lei a Abolição da escravatura); sobre a República (Manifesto Republicano e mais) e ainda contando com as reformas educacionais (Lei de 1827, Ato adicional de 1834, o Regulamento de 1854 e a Reforma Leôncio de Carvalho de 1879), mais do que defender a liberdade do homem, por exemplo, Tobias Barreto defendia uma nova ordem política, econômica e social. Para isso, baseou-se num repertório vasto, sobretudo alemão, e que foi da crítica ao direito natural e ao catolicismo em voga no Brasil até o diagnóstico da situação política do país, o que incluía a censura ao poder moderador e à escravidão. Contemplou também a crítica à cultura do brasileiro que abrangia a falta de compromisso público com a educação da mulher e a educação profissional de uma maneira geral. Era 1870 quando ele foi taxativo:

Se houver a imprudência de aí erguer-se um brinde à liberdade de consciência, o Brasil não o poderá acompanhar, porque mantém em si a escravidão religiosa; se um brinde à liberdade natural ou civil, o não poderá satisfazer, porque tem o escravo; se um brinde à liberdade política, não o poderá satisfazer, porque não tem o cidadão. (BARRETO apud BARRETO, [1870] 2012e, p. 368). 
$\mathrm{Na}$ linha de frente de suas análises e diagnóstico esteve o Imperador Pedro II e a política brasileira. Na visão de Barreto, além da sua limitada ação governamental e de mal assessorado por ministros corruptos, Pedro II não merecia a propaganda de que o Brasil era o "Gigante da América" e que ele era um monarca de "alta estatura" e de "ótima administração". Para Tobias, tais afirmações eram absurdas, dado que o Brasil encontravase em atraso econômico e cultural. Ressaltou, ainda, que a despeito da boa imagem que os correligionários se predispuseram a "pintar" nas páginas dos jornais brasileiros e estrangeiros, de que o Imperador era um homem culto, bem relacionado, um amante das artes e da ciência, o Brasil estava precisando de urgente reforma. O autor de Monografias em Alemão assim esclarece:

Apesar de não pertencer àqueles que, por motivos políticos, atribuem unicamente ao Imperador a causa do nosso atraso, e que quase responderam à pergunta: "Por que grassa no Rio de Janeiro a febre amarela? - Porque o Imperador o quer" pretendo, todavia, confessar que esta nobre personalidade, à que não custa muito ser tida como altamente formada sem o ser realmente, ela tem não pouca culpa pela defeituosa cultura, que nos prejudica. Ainda que os bajuladores muito se esforcem em adocicar a pílula, não é possível engoli-la toda. De fato: quem é que não ouviu ainda falar do surto maravilhoso, que tomou o interior desenvolvimento geral do Brasil, sob o Governo do Imperador Pedro II? O Imperador seria uma cabeça pensante, atraindo a atenção do mundo dos sábios. Levado pela mão do seu amado monarca, o Gigante da América estaria escalando uma altura inaudita. O bom estímulo imperial estaria, sem cessar, levando-nos para a frente, quer dizer, nosso mandatário estaria cavalgando segundo os princípios do Direito. Por isso deveríamos estar contentes e orgulhosos do nosso Tito... etc. Ora, tudo isto é puro engano e mentira! Que eu consiga envergonhar os mentirosos. (BARRETO, [1875] 1990, p. 127, grifo do autor).

Arremata o diagnóstico da seguinte forma:

O governo de Dom Pedro pode ser tudo, exceto intencionado liberalmente, sequer conforme a Constituição. O poder monárquico no Brasil, que brota total e completamente do arbítrio de Dom Pedro, não sabe colocar-se acima da estreiteza dos partidos e das lutas de interesses, ele se deixa muito mais se desenraizar pela predileção por um partido, através do vento contrário das eleições, e é causa de ter caído até zero o grau de temperatura do patriotismo não entre as piores, muito mais entre as mais honestas de milhares de almas. Eu, pelo menos, estou certo a propósito a minha posição diante de Dom Pedro e sua astuta política de raposa. Constitucional no nome, na realidade o Brasil é uma monarquia absoluta, moderada através da frase, ou, se se quiser, uma monarquia francesa elaborada à maneira brasileira. Se fosse aplicável, a uma palhoça como a um palácio, eu poderia adaptar ao Brasil as palavras de Byron em relação à Inglaterra: o grande primum mobile deste país é declaradamente a mentira - mentira política, a mentira poética, a mentira religiosa, a mentira moral, mas sempre mentira, que se repete em todas as fases da vida. E como a mais colossal de tais mentiras, de necessidade e conveniência, destaca-se a figura do Imperador, seu liberalismo, sua alta educação. Malfadados tempos - escrevia Treitschke - se os personagens cômicos começarem a desempenhar um papel trágico! Vivemos em tais tempos, a saber, sob o governo de tais cômicas figuras. (BARRETO, [1879] 1990, p. 175-176).

Era 1871 quando Barreto, ao analisar o governo e o poder moderador como prognóstico, assim considerou:

Logo, o único meio de salvar e engrandecer o Brasil é tratar de colocá-lo em condições de poder ele tirar de si mesmo, quero dizer, do seio da sua história, a direção que lhe convém. O destino de um povo, como o destino de um indivíduo, 
não se muda, nem se deixa acomodar ao capricho e ignorância daqueles que pretendem dirigi-lo. (BARRETO, [1871] 2012c, p. 100).

Dizia com isso que mais do que está, o Brasil, submetido à ignorância dos seus líderes, o seu povo deveria retirar da sua própria história a experiência para formar-se cidadão. Baseando-se no jurista e teólogo francês Edmund Scherer, encontrou uma solução para a direção do país:

E penso como Edmund Scherer que o meio de dirigir, nas sociedades modernas, não é persuadir discutindo - é conciliar obrando. Não se convence os espíritos senão por uma inciativa, grande, fecunda, sempre nova. É mister marchar adiante, para fazer-se seguir; arrastar, para conduzir; assombrar, para subjugar. (BARRETO, [1871] 2012c, p. 102).

Obrar, arrastar, assombrar, eis as palavras de ordem que deveriam reger o brasileiro que, em muito, carecia de inciativas e ações concretas em seu próprio benefício. No transcurso do texto, Barreto dá a entender que, ao contrário dos ingleses, aos brasileiros faltava o espírito de "associação" que concorreria para o "bem geral". Segundo ele, os brasileiros, de uma maneira geral, como consequência do seu "egoísmo", acabavam com receio de comprometer-se trabalhando para o coletivo, o que os tornava alvos da "tirania das coisas" e da "pressão das circunstâncias".

Numa sequência lógica de entendimento da política brasileira, do perfil de seu povo e dos modelos políticos estrangeiros, Barreto envereda em acirrada disputa de erudição e de egos com seu colega professor, o pernambucano José Higino. Por certo, como forma de contribuir com a organização da sociedade brasileira, muitos foram os modelos políticos que foram pensados para o Brasil, como por exemplo, o selfgovernment, defendido por Higino. Barreto, todavia, ao analisar o trabalho do colega, e consequentemente a opinião dele, a rechaça, considerando para isso o fato de que para que tal modelo saísse a contento, o povo deveria ter uma boa educação política. Assim se expressou:

\begin{abstract}
Esta ideia, que não deixa de ter partidários insignes e ocupa algum lugar no espírito e nos livros dos pensadores ingleses, é apenas excelente para alimentar a nossa fatuidade. A grei dos publicistas e oradores liberais, que nos regalam todos os dias com os seus sonhos de monarquia parlamentar, não cansa de nos pintar, a seu modo, as maravilhas do Selfgovernment. Não se lembram, porém, de que o Selfgovernment tem por adjunto a self-reliance, o sentimento da confiança em si mesmo, no próprio esforço de cada um; e este sentimento é de tal natureza que não se desperta facilmente na alma de um povo esmorecido por sua má educação política. (BARRETO, [1871] 2012c, p. 103, grifo nosso).
\end{abstract}

Estava, com isso, considerando não somente a má educação política do brasileiro, mas o que dela resulta em termos de ação individual, de comprometimento com o espaço público e a consequente incapacidade do Brasil em assumir uma forma de governo como o selfgovernment, inclusive evocada pelos liberais de plantão, mas que não tinha, nas circunstâncias locais, razões de ser.

Ainda considerando o poder avaliativo de Tobias Barreto em relação à situação política do país, em 1872, no texto sobre "A província e o provincialismo", ele não somente expôs um exame sobre os ministérios, como incitou aos jovens políticos a repensarem sua futura atuação: 
É tempo de acabar com as ilusões; tenhamos ao menos consciências da nossa obscuridade, e não nos exponhamos ao ridículo, com burlescas pretensões daquilo que não somos. Creio ser este, e só este, o caminho que nos dirige a melhorar de sorte: reconhecer que não temos homens notáveis e capazes de dar impulso ao nosso corpo social. Fala-se muito mal do imperador; e ele merece; mas releva não esquecer que tudo não provem dessa fonte. No dia em que o monarca encontrar ministros tais, que diante deles só possa fazer uma triste figura, que não possa "tugir nem mugir", com medo de dizer alguma asneira; adeus, governo pessoal, adeus, governo de um só! E isto sem barulho. Mas assim como temos andado com ministros de cultura inferior à do rei, que sabem menos do que ele, desde a "estupenda cabeça" do Sr. Zacarias até a farda do Sr. João Alfredo, passando pelos Paranhos, Pimentas Buenos, Alencares, e todos os outros... A coisa é impossível. Pensem nisso os velhos desabusados e os moços que ainda não transigiram. (BARRETO, [1872] 2012c, p. 157).

Como pode ser percebido, ele confere a inferioridade cultural dos ministros o tipo de governo que se tinha e, a medida que entende isto, expôs a ideia de que na ascensão cultural dos membros dos ministérios estaria um dos remédios para os males da ignorância do país, que incluía não somente a administração pública, mas a própria formação do cidadão. Cidadão este que, como afiançou Marshall (apud BARRETO, 2012), para ser formado, carecia de direitos necessários à liberdade individual; do direito de participar no exercício do poder político, de um mínimo de bem-estar econômico e segurança e do direito de participar, por completo, da herança social. Nesse sentido, seriam os pobres, as mulheres e os negros, cidadãos?

No texto "Socialismo em Literatura", de 1874, Barreto se dedicou ao tema pelo viés literário e comungando com a máxima "o socialismo é a luta contra a luta pela existência" assim analisou:

Nos países atrasados e - o que ainda é pior - sem consequência do seu atraso -, ao lado do capital econômico, mal adquirido e ocioso, que subjuga o trabalho do braço, avulta um outro, não menos importuno, que faz frente e põe obstáculos 0 trabalho da cabeça. (BARRETO, [1874] 2012a, p. 109).

O capital que ele tratava era o capital dos "espíritos medíocres", que se enalteciam quando comparados com a ignorância geral e que, por isso, não se esforçavam para conseguir sua "reputação intelectual". Reputação essa que, segundo ele, deveria ser "irreparável". A partir desse e de outros elementos, ele conclama que os brasileiros se erguessem "contra as tradições recebidas" e que mudassem o "curso da história". Prossegue seu texto tratando das retaliações recebidas pelos críticos, deixando claro que a crítica não era bem recebida e que havia determinadas figuras que não admitiam ter a sua atuação posta em análise. Querendo ser exemplo daqueles que recebem bem as críticas ele se expõe e revela que era considerado, por muitos, pessimista, ao que ele responde que, não só era pessimista como considerava o pessimismo algo benéfico, na medida em que não havia "progresso" e "conquista" sem pessimismo sincero e convicto, e mais, concordava com Agnes Taubert em sua obra Der pessimismos und seine Gegner, quando este considerava ser o pessimismo uma "ideia de primeira ordem, um princípio dirigente da civilização hodierna".

Como forma de ratificar o seu papel de crítico e seu poder analítico, lançados nas páginas dos jornais pernambucanos ou mesmo nos artigos publicados na capital do Império, no Rio Grande do Sul e na Alemanha, o pessimista convicto atacava a França 
considerando um "modelo de inteligência moderno" mefítico e a Alemanha, como modelo a ser seguido, através do que ele chamou de "reforma intelectual"2. Sobre a crítica e o seu poder, ele expôs:

A Crítica inexorável, a crítica aniquilante, deve ser a nossa palavra de ordem. No estado em que jazemos, assenta-nos de alto a baixo o que disse uma vez da sua terra Massimo d'Azeglio: Itália é fata, magliitaliani no ancora sonfatti. [Sic] Também nós não estamos feitos. Sem exageração, sem pathos retórico: o espirito brasileiro, em mais de metade, plonge dans la abrute (estão imersos na matéria). (BARRETO, [1874] 2012a, p. 113).

Segue argumentando, em forma de diagnóstico, que

A candidatura do Brasil aos foros de nação culta é um fenômeno mórbido: alguma coisa de semelhante ao disparate dos loucos, que se julgam reis. Que cultura se concebe para um povo cuja religião, cujas políticas são puramente mecânicas? E que religião, e que política pode haver em um país, onde a filosofia é nula, onde a arte é nula, onde a ciência é nula? - Eis aí tudo. (BARRETO, [1874] 2012a, p. 113).

A análise do que representava a apropriação da cultura estrangeira foi, por certo, uma crítica contundente do "francesismo" tão em voga na corte brasileira, mas também, como já ressaltado, a falta de identidade cultural e de produções filosóficas e científicas genuinamente brasileiras. Não foram poucos os artigos de Tobias enaltecendo países europeus, sobretudo a Alemanha, fossem o aspecto cultural, educacional ou mesmo político e econômico. Entretanto, nenhuma das críticas pareceu ser levada adiante, exceto pelos seus seguidores, em gerações distintas. Como principal exemplo está o seu conterrâneo e contemporâneo Sylvio Romero, o seu também colega Artur Orlando e os seus ex-alunos Clóvis Bevilacqua e Graça Aranha, dentre outros que, de uma maneira ou de outra, levaram o pensamento do "mestre" às páginas das histórias das ideias filosóficas e jurídicas brasileiras.

\section{A política como espaço para escoar as angústias}

O repertório estrangeiro, por sua vez, não foi o único mobilizado por ele ao sugerir alternativas ao Brasil. Ele demonstrou conhecimento das potencialidades brasileiras, o que advem não somente do seu papel de crítico político e social, mas também de político a par dos problemas do país. Um exemplo significativo data de 1878, quando ele exercia o mandato de deputado provincial em Pernambuco e assim sentenciou a missão do governo:

Criar escolas para o ensino agrícola, abrir vias de comunicação, fundar bancos rurais, que livrem os agricultores da agiotagem dos correspondentes, animar e facilitar todos os trabalhos que aumentem o valor da terra, essa inesgotável e sempre generosa da fortuna dos povos, eis a missão do governo. (BARRETO, [1878] 1994, p. 100).

Com tais medidas, acreditava Tobias Barreto de Menezes que o Brasil poderia

${ }^{2}$ Ao atentar para a bibliografia, sobretudo da obra de Tobias Barreto e de seus contemporâneos foi possível chegar a algumas conclusões, a saber: Tobias Barreto foi um leitor voraz da produção contemporânea estrangeira, o que demonstra sua sagacidade e preocupação em enveredar por outras culturas julgando-as umas melhores que outras. São muitos os autores mobilizados e muitas as culturas evidenciadas em seus exemplos. Da mesma forma que também são muitos os juízos de valor que revela em seus artigos. 
avançar rumo a uma nova ordem em que o povo também se sentisse responsável pelo destino do país. Por certo, nos discursos de políticos e/ou intelectuais brasileiros, fosse em livros, artigos de jornais, em mandatos políticos, cargos públicos ou mesmo no magistério, a tônica que vinha das leituras e traduções priorizava as teorias e práticas educacionais que implicavam o novo, o moderno e a modernização. Em detrimento das velhas práticas que teimavam, e, por certo ainda teimam, em permanecer no campo político, e, corroborando com a ideia de alavancar o país pela educação e formação de quadros profissionais, muitos "intelectuais", pensaram a organização da sociedade brasileira durante o século XIX. No caso de Barreto, ao tempo que teceu críticas ferozes aos autores brasileiros, mobilizou ideias de autores estrangeiras a fim de agregá-las às suas. Nesse sentido, salvo raras exceções, em seus artigos, ele buscou destituir concepções religiosas e positivistas enveredando por um "culturalismo filosófico" ${ }^{3}$. Para tanto mobilizou os repertórios de Charles Darwin, Ernest Heckel, Rudolf Von Jhering, Eduard Von Hartman, Noiré e Imannuel Kant, dentre outros autores alemães para elaborar sua análise sobre a organização da sociedade, tendo por escopo acabar com o quadro fatal da sociedade escravista brasileira e, por fim, a liberdade do homem.

Nesse sentido, uma concepção de educação é identificada e vem ao encontro de uma possível ascensão intelectual do povo brasileiro. Como pôde ser vislumbrada, a ideia recaiu na profissionalização do rurícola, mas também na educação feminina em nível superior, o que segundo ele, seria a maneira de acabar com o atraso advindo do desprestigio e preconceito do "sexo frágil" e igualar a capacidade de trabalho da mulher ao do homem. Assim, sua proposta de instituição educativa (paternogógio) baseou-se nos autores Friedrich Adolf Wilhelm Diesterweg, Friedrich Froebel e Johann Heinrich Pestalozzi para quem, de uma maneira geral, a educação deveria primar pela autonomia e atender a todos indistintamente. (BARRETO, 2015).

Nesse sentido, para alem da educação que deveria ser dispensada a mulher, a partir das edições do Jornal $O$ Industrial, o qual Tobias foi um dos dirigentes e articulistas, é possível entender o peso da cultura, da ciência e da técnica em seu pensamento acerca da educação. Isto porque era pelo uso do produto da ciência que se chegaria ao progresso econômico e ao bem estar da sociedade, contrariando os preceitos senhoriais e escravocratas. O objetivo de Tobias, segundo os seus artigos do referido jornal, era que a organização da sociedade se desse a partir das potencialidades e possibilidades do povo e não da exploração deste pelos detentores de capital. Nessa seara ele expõe a sua concepção do direito como produto cultural, da liberdade como alvo da conquista do povo e da educação como meio de ascensão intelectual e econômica.

Em estudo anterior (BARRETO, 2015) dedicado às ideias de Tobias Barreto e onde foi analisado, dentre outras fontes, o referido jornal, foi possível perceber o quanto a agricultura vinha ocupando o primeiro lugar das atividades de países cultos e laboriosos. No artigo foi destacado que o jornal diferenciava quais os papéis do Estado e do dono da indústria, sendo a este atribuído a responsabilidade financeira e àquele a de formação dos operários. Em certa medida, assim está sintetizado os temas ali tratados e que remetem ao ensino para o trabalho:

3 Termo atribuído por Sylvio Romero ao modo como Tobias Barreto pensou o Direito a partir da Filosofia. 
Traz o exemplo da Prússia onde o primeiro ministro deixa claro que nada pode concorrer para o enfraquecimento de uma nação como "o pouco amor a instrucção, e o desconhecimento dos benefícios que a terra prodigalisa." A edição traz também, para além de uma discussão sobre o que precisa a indústria brasileira, exemplos concretos do que pode ser feito a fim de melhorar a área. Nos artigos sobre motores solares; ensino agrícola, a indústria do algodão e o seu possível desdobramento em outras indústrias como por exemplo aquela dedicada ao seu caroço; sobre os meios de transportes e a sua indicação de um sistema de transporte nacional contando para isso com os exemplos da Inglaterra, França e Holanda; sobre os engenhos centrais e as implicações de não atender a divisão social do trabalho já experienciada em países desenvolvidos, sem contar com a apologia a agricultura como sendo a indústria que possuímos e que merece investimentos, há uma gama de indicações que vão além do liberalismo e envereda por uma necessidade de investimento na formação dos "operários". (BARRETO, 2016, p. 106).

Outro elemento importante, que envolve a concepção de educação do sergipano radicado em Pernambuco, está contido no artigo As artes e a indústria artística de 1883. Neste ensaio, ele ratifica de maneira mais especifica o ensino das artes como um dos passos para o desenvolvimento, atribuindo ao Estado a "sólida educação dos artistas" e por isso, considerou ilógica a teoria liberal de que o Estado contrariaria a "natureza das coisas", se influísse nos domínio da vida cultural, econômica, jurídica, artística, religiosa e científica da nação. Para ele:

O esperar tudo do Estado, não menos que o esperar tudo de Deus, é um fenômeno patológico, é um sintoma de doença, um documento de preguiça. Mas daí não se deduz que os indivíduos e os povos só tenham a depositar confiança em si mesmos, com exclusão de qualquer concurso do alto. Não foi Deus quem disse, como the atribui o provérbio, mas é o Estado quem deve dizer: faze que eu te ajudarei. (BARRETO, [1883] 2012b, p. 188).

Mesmo considerando o que acontecia em outras províncias, o ponto de partida da análise de Barreto, embora tivesse restrito ao norte do país, mais precisamente na provincia de Pernambuco e em alguns casos a partir da cidade de Escada onde residiu por 10 anos (1871-1881), foi suficiente para buscar as origens e os principais pontos nevrálgicos de letargia brasileira. Como já insinuado, encontrou, sobretudo, na falta de preparo do seu povo a maior causa. Soma-se a ela a também já ressaltada má administração política do país e o "defeito de carater nacional" do seu povo. Ao eleger a cidade de Escada como lócus de uma de suas muitas análises, ele deixa claro quão insensível poderia ser a classe política ao destinar os maiores percentuais à polícia em detrimento da educação, por exemplo. (BARRETO, 2015).

Ao atentar, no mesmo artigo, para os montantes destinados às artes, fosse estimulando a formação de artistas, fosse comprando e preservando as obras de arte de países como França, Bélgica, Prússia e ainda a Saxônia e a Baviera, ele surpreende ao chegar a conclusão de que:

Antes de tudo, a situação geral das finanças de qualquer país é que deve dar a última palavra sobre essa questão. Se ela é de tal natureza que, feitas as despesas necessárias, e sem opressão dos contribuintes, ainda há um supérfluo que possa ser aplicado à arte, não há dúvida de que a aplicação é das mais úteis. Mas nós não queremos afagar ilusões. Qual é aí o país. - e o nosso menos que todos capaz de apresentar esse supérfluo de sua receita? Cremos que nenhum. Já se vê que a partir daquele princípio, que aliás é justíssimo, nunca se chegaria ao fim 
desejado. O que importa pois é buscar tirar o melhor partido do mau estado financeiro mesmo, em que nos achamos. (BARRETO, [1883] 2012b, p. 190).

Prossegue seus argumentos deixando claro que, no caso do Brasil, seria insensatez destinar verbas para tais fins, ponderando, sobretudo, que os costumes de um povo inculto não se mudam contemplando obras de arte e, nesse sentido, afirma que a arte antes de aparecer como passatempo, deve ser considerada uma atividade prática, como uma "categoria do trabalho". E é justamente sob esse prisma, o do trabalho, que Tobias considera o auxilio do Estado em algo que fosse além dos liceus de artes e ofícios. Também nesse campo, como já revelado, o autor do artigo As flores perante a indústria ressalta a necessidade e os benefícios da educação da mulher e a sua consequente participação no mercado do trabalho e por extensão na economia do país. Ao analisar a educação oferecida as mulheres e a sua pretensa compreensão de uma educação profissionalizante tendo por base o cultivo das flores, sob a ótica da botânica e com um potencial de mercado significativo, ele assim se expressou:

\begin{abstract}
Nenhuma das nossas escolas públicas se ocupa de tal matéria, e os pensionatos ou colégios, a cargo de particulares, talvez não tenham sequer o pressentimento da coisa. Nestes pensionatos há horas consagradas ao passeio e ao recreio, mas ninguém se lembra que não se concebe melhor recreio do que entreter-se com as flores, não no sentido de uma coquetterie, ainda mesmo inocente, porém no de uma ocupação salutar. (BARRETO, [1883] 2012b, p. 196-197).
\end{abstract}

Segundo o autor, as instituições educativas, respeitando o seu regimento e a sua "missão educacional", não foram capazes de impulsionar a cultura letrada de seus alunos dotando-os de um capital suficiente para divulgar e expandir uma cultura escolar profissionalizante que contemplasse a real necessidade do Brasil em modernização. Ao que parece, na ânsia de imitar ou transplantar uma cultura escolar estrangeira, não se considerou, pelo menos nos moldes de um país eminentemente rural, as reais e verdadeiras necessidades de educação do seu povo. Se se considerar a situação dos escravos alforriados, que sem formação não tinham emprego e remuneração para seu sustento; das mulheres pobres e sem formação específica para as quais não existia mercado de trabalho e, muito menos, para boa parte dos homens pobres sem formação, para os quais restavam apenas os trabalhos baseados na força física, impedindo de trabalhar aqueles que não a tinham, o quadro educacional do período ganha perspectiva de análise ainda mais importante.

Nesses termos, os movimentos abolicionistas não foram organizados suficientemente para que os homens e mulheres, uma vez livres, tivessem formação para adentrar no novo universo de trabalho caracterizado, dentre outras coisas, pelo trabalho remunerado. Evidência disso foi o grande contingente de ex-escravos que "sobreviveram" em condições deploráveis em busca de trabalho, não o encontrando. Nesse cenário, onde figuravam de um lado uma legislação específica que orientava a instrução, reformas que primavam pela regulação do ensino primário, e secundário, defesas dos políticos e intelectuais de plantão, e, do outro, um público heterogêneo, necessitando de instrução e formação condizentes com o novo projeto de nação que se estava encetando, os intelectuais da educação do império pensaram seus projetos e, na medida do possível, os encabeçaram. Tal público composto de crianças e jovens de famílias abastadas, da mesma forma que de família pobre, ex-escravos, filhos de estrangeiro de língua distinta, meninos 
e meninas abandonadas, moças em idade de trabalho e sem qualificação profissional, dentre outros compunham a população brasileira e foi, no caso de Tobias Barreto, o ponto de partida para suas ideias e propostas que envolveram a educação.

Um exemplo que também merece atenção nesse artigo, pois contempla a sua visão da mulher e o que ele pensou acerca da sua função, educação e direitos, está no seu estudo sobre os "Menores e Loucos", datado de 1874. Nele é traçado um panorama dos direitos àqueles relegados, mas começa por considerar as diferenças que afligem os gêneros e mais que igualá-los o que ele fez foi apontar caminhos que, a partir das diferenças, se propôs como justo. Começa pelas seguintes indagações:

[...] por que razão o Código, determinando a idade, em que começa a imputação criminal, não estabeleceu diferença entre o homem e a mulher? Que motivos de ordem moral ou política o levaram a igualar os dois sexos, sob o ponto de vista jurídico-penal, quando eles são tão desiguais na esfera do direito civil? É o que trato de elucidar. (BARRETO, [1874] 2012d, p. 56).

Baseando-se no caso do Brasil e nas disparidades legais, culturais e educacionais relativas ao gênero, com destaque para o desprezo às descobertas cientificas e ao "novo" papel atribuído às mulheres em nações desenvolvidas, revelando erudição, ele é taxativo no tocante ao conceito de sociedade:

A sociedade é um sujeito para o qual há muito que se procura um atributo. Ela não é, nem será jamais o que Jesus queria que fosse: a organização do amor. Ainda não é também, nem a de ser tão cedo, o que Lorence Stein e Hartaman pretendem que ela seja: a organização do trabalho. Diante, porém, de semelhantes fatos, creio ter descoberto o verdadeiro predicado: a sociedade é simplesmente a organização da hipocrisia. (BARRETO, [1874] 2012d, p. 58).

Palavras como hipocrisia, mediocridade e ignorância são muito comuns no vocabulário tobiático e revelam mais do que a crítica e o espírito interpretativo do autor, relevam uma predisposição ao embate e o seu espirito aguerrido, alimentado diariamente pelo olhar sensível aos fatos cotidianos que envolviam o direito e a condição econômica, social e, sobretudo cultural do seu povo e dos seus governantes. Quando pondera que a sociedade é a organização da hipocrisia, estava baseando-se na "anomalia" da desigualdade civil e política entre os gêneros e que não via sentido em diferenciar o homem da mulher em qualquer das esferas.

A ideia de igualar a mulher ao homem no direito penal fez com que alguns elementos de ordem prática fossem evocados e sistematicamente retaliados por Barreto, pois não envolviam descobertas científicas acerca da compleição física, do tamanho e da função cerebral que não mais justificavam as diferenças perpassadas culturalmente de geração para geração. Lembrava ele:

Ainda estão vivas as belas palavras de Olímpia de Gourges, que eu me permito inverter e repetir: enquanto a mulher não tiver, como o homem, o direito de subir à tribuna, ela não deve ter igualmente com ele, nas mesmas proporções que ele, o direito de subir ao cadafalso. (BARRETO, [1874] 2012d, p. 60-61).

Um outro elemento por ele desenvolvido contempla o estudo do caráter pedagógico do direito, bem como do seu poder de reparação e adaptação do homem à sociedade, potencializando assim a relação do direito e educação. Segundo ele: 
Também o direito, máxime o direito penal, é uma arte de mudar o rumo das índoles e o curso dos caracteres que a educação não pôde amoldar; não no sentido da velha teoria da emenda, no intuito de fazer penitentes e preparar almas para o céu, mas no sentido da moderna seleção darwinica, no sentido de adaptar o homem a sociedade, de reformar o homem pelo homem mesmo, que afinal é o alvo de toda política humana. (BARRETO, [1874] 2012d, p. 80).

Com base nas referências da época, a exemplo de Lombroso, Carlos Ernesto Baer, Lazarus Geiger, dentre outros, ele discute rudimentos que compõem a ciência do direito, a exemplo do crime, da causa, do dolo, do acaso, da premeditação, da imperícia, e da impudência, dentre outros, e aduz um conceito amplo e restaurador, ao contrário do direito meramente punitivo e sem caráter educativo. Tal concepção também incorporou representações que contemplaram aspectos da vida diária brasileira e que servem de mote para o entendimento do espaço social e suas implicações na formação do cidadão. As tensões humanas, que sobressaem nos seus exemplos, igualmente servem de chave de leitura da realidade brasileira e ao fazê-la pelas lentes do Direito, acaba por conceber a educação como meio de igualar os homens, embora considerando suas particularidades.

No ensaio escrito entre 1874 e 1881 ele se dedica a "Alma da Mulher" e, para além de fazer uma revisão da literatura dedicada ao gênero feminino e às suas predisposições, monta uma linha de defesa que enfatiza a formação e o trabalho da mulher como um dos caminhos a serem seguidos pelo Brasil, que se propunha moderno. Segundo ele:

\begin{abstract}
Já é tempo, meus senhores, de irmos compreendendo que o belo sexo em Pernambuco, bem como no Brasil inteiro, tem direito a maior soma de instrução do que lhe tem sido até hoje fornecida pelos poderes públicos. A escassa instrução elementar que a província proporciona às suas filhas não satisfaz, não pode satisfazer às exigências da época. A chamada secundaria, que é dada nos colégios particulares, como raríssimas exceções, está abaixo de qualquer crítica; e a superior é totalmente nula. Por uma velha metáfora consagrada costuma-se dizer que a instrução é o alimento do espirito. Dou que seja; mas também é força confessar que esse alimento, pelo que toca às mulheres, ainda se limita a podres migalhas caídas da parca mesa da cultura masculina, ou antes, para servir-me da expressão de uma escritora alemã contemporânea, Josefina Freytag, o alimento espiritual do belo sexo - são confeitos, em vez de pão. Sim, nada mais do que confeitos; e a relação de semelhança conserva-se até na propriedade de enfastiar e indispor o espirito para tomar o verdadeiro sustento. Assim, um pouco de música, algumas peças de salão para o piano, um pouco de desenho, gaguejar uma ou duas línguas estrangeiras e ler as bagatelas literárias do dia, eis o total da maior cultura do sexo feminino em nosso tempo, cultura anômala, que E. Von Hartmann justamente qualifica de instrução sistemática da vaidade, e que, entretanto, não é preciso dizê-lo, redobra de esterilidade e de penúria entre nós. (BARRETO, [1874/1881] 2012b, p. 68-69).
\end{abstract}

Ao ponderar a educação até então ministrada à mulher no Império, para além de considerá-la "inútil, e quase se podia dizer perniciosa e fatal", ele concebe a educação ministrada como uma espécie de aparelho ideológico do Estado a medida em que servia de instrumento para conformar e não emancipar. Na visão dele:

Se já houver quem opinasse que a arte de ler e escrever, sem cultura espiritual propriamente dita, é mais um mal do que um bem, pois importa para os agitadores um meio seguro de propaganda, tendo eles por esse modo um rebanho de leitores dóceis, que não refletem, que não reagem criticamente, parece que isto é aplicável com igual, se não maior, propriedade á instrução elementar feminina. (BARRETO, [1874/1881] 2012b, p. 69-70). 
Ao considerar, entretanto, que a instrução da mulher é um fato que já fazia parte do curso da história e que a mulher brasileira "é, em geral, guardadas as proporções, mais inteligente que o homem" ele evoca o holandês Van der Wyk para argumentar sobre a necessidade de mulher instruída no Brasil. Para tanto, traz à análise a diferença entre a mulher sábia, não necessariamente instruída e educada, e a mulher instruída, ressaltando que é este o tipo de mulher que importa para um país que se pretende moderno, pois a instrução somada à agilidade, vivacidade e poder de conversação, próprios da mulher, a faria mais produtiva. Considerando a concepção da época de alguns de seus colegas de profissão, que atribuíam à mulher o trabalho doméstico e quando muito o professoral e que consideravam que o seu envolvimento com a ciência, poderia ser letal, ele assim responde: "A ciência não seria digna dos nossos preitos, nem dos nossos sacrifícios, se nas mãos da mulher ela sempre se transformasse em instrumento de perdição". (BARRETO, [1874/1881] 2012b, p. 71). Tratava, assim, da função do conhecimento e do seu suposto mau uso pela mulher.

Outro fato que merece destaque e que é recorrente nas suas críticas, como pôde ser demonstrado é que, embora crítico ferrenho ao imperador, Tobias não atribui a ele todos os males da vida política e social do país. Segundo ele, o que é recorrente em seus escritos. A inanição política dos municípios, bem como "mil fenômenos patológicos do organismo social brasileiro" como, por exemplo, a falta de civismo dos cidadãos e mesmo a desonestidade dos donos de engenho e dos "cafeocratas", não eram culpa de Pedro II. E acrescenta: "Se a nossa vida intelectual é quase nula, se a instrução pública é mínima, o imperador tem bem pouco ou nenhum parte em semelhante estado de coisa". (BARRETO, [1874/1881] 2012b, p. 77). Seu argumento se intensifica quando ele assim trata das consequências do Ato adicional de 1834:

A propósito de instrução basta lembrar que 0 ato adicional pôs 0 seu desenvolvimento a cargo das províncias sem dependências do poder central; e, todavia, qual o progresso sensível que ele tem feito? Será por causa do veto imperial que até nas capitais das províncias de primeira ordem não existem, por exemplo, estabelecimentos públicos de humanidades para o belo sexo? Ou, se isto é muito, será pela mesma coisa que, em matéria de analfabetismo, temos a honra de emular com a devota Espanha? Respondam os entendidos. (BARRETO, [1874/1881] 2012b, p. 77).

Com tais indagações e com o sarcasmo que the era próprio, ele colocava em evidência não somente o poder decisório das províncias, mas também a sua má atuação em prol da educação. Na condição de deputado provincial de Pernambuco e depois de vereador do município de Escada, ele conheceu ações e tensões que fugiam ao poder do imperador, a exemplo da falta de consenso entre os pares, o que, para ele, mostrou-se elemento significativo para justificar as mazelas locais. Por certo o reconhecimento das limitações do imperador frente aos problemas provinciais, sobretudo àqueles ligados a educação, não foram suficientes para que Tobias se inibisse em criticá-lo quando do tocante às questões político-administrativas que atingiam todo o país. Um outro exemplo que merece revista está relacionado à sua relação com o escravismo. Em texto também composto entre 1874 e 1881 e dedicado a "Organização Comunal da Rússia", ele aproveita e, em tom de escárnio, explica: 
D. Pedro tem sido, como ainda é, a única força histórica do nosso desenvolvimento. No sentido inverso, é verdade, do que devera ser; mas sempre uma força. Se menos sinérgica do que antagônica e perturbadora da marcha evolucional do Estado, e até hoje incapaz, por capricho, de eliminar as irregularidades dominantes no processo cromogenético, ou biológico nacional, aí mesmo é que reside o motivo do seu denegrimento perante a história; e é isto que também, no meu sentir, determina e justifica o pouco amor que the consagro. (BARRETO, [1874/1881] 2012b, p. 78-79).

Atribuir ao Imperador a decisão de acabar com a escravidão e em páginas outras tratar da liberdade como princípio da ordem, contradiz a visão de autores como Evaristo de Moraes Filho, que o teve na condição de racista, pois o considerava "omisso", "ausente" e até mesmo "desafeto" da causa abolicionista. Luiz Antonio Barreto (1994) por sua vez, com objetivo de esclarecer os adjetivos atribuídos, desenvolveu um estudo sobre Tobias Barreto e o preconceito racial, e, na pesquisa, destaca a atuação dele perante o escravismo brasileiro. Para tanto, traz à luz os casos do cerco à sua casa em Escada, quando do caso que envolvia a libertação de escravos herdados e o fato de que, assim como muitos poetas do seu tempo, "também engajou a sua poesia na defesa da liberdade dos negros. $E$ o fez de três formas: exaltando a morena, mestiça brasileira, deplorando a escravidão, de forma explícita, e inflamando as massas em torno das ideias de liberdade." (BARRETO, 1994, p. 88) Ainda na opinião de Luiz Antonio Barreto "Mais do que alforriar escravos, defendê-los como Curador, e protegê-los como advogado fiscalizando a ação da justiça, Tobias Barreto dedicou parte de sua permanência em Escada para denunciar as diversas formas de injustiças ali praticadas contra os negros e contra o povo." (BARRETO, 1994, p. 94).

O poema A escravidão é um dos seus principais "Salvo-conduto" da antonomásia de racista. Nele, o mulato sergipano deixa claro sua crítica às instituições sociais, a exemplo da Igreja e do Estado, e atribui à geração mais nova a correção do erro que era a escravidão. Assim tratou a temática:

\author{
A escravidão \\ Se Deus é quem deixa o mundo \\ Sob o peso que o oprime, \\ Se ele consente esse crime, \\ Que se chama a escravidão, \\ Para fazer homens livres, \\ Para arrancá-los do abismo, \\ Existe um patriotismo \\ Maior que a religião. \\ Se não lhe importa o escravo \\ Que a seus pés queixas deponha, \\ Cobrindo assim de vergonha \\ A face dos anjos seus, \\ Em seu delírio inefável, \\ Praticando a caridade, \\ Nesta hora a mocidade \\ Corrige o erro de Deus!...
}

Atribuir à mocidade a correção dos erros de Deus foi a evocação encontrada por Barreto não somente para acabar com a escravidão, mas com outras mazelas do Brasil, como por exemplo a corrupção politica e sobretudo a baixa instrução do povo. Quando pensou a organização da sociedade sob a batuta dos teóricos alemães e usou da observação e crítica para chamar a atenção da mocidade para os problemas brasileiros 
encontrou na emanacipação feminina via educaçao e instrução uma das soluções para, não somente modernizar o Brasil, mas tambem para gerar economia. Quando pensou nos homens livres propôs uma educacão para o trabalho, também voltada para a emancipação, sobretudo economica, em que poderiam ser alocados ex-excravos, pobres para além de mulheres.

\section{Considerações finais}

Ao considerar a divisão suscitada por Weber entre o político e o cientista, dado que existem políticos que se tornaram homens de ciência e homens de ciência que se tornaram políticos durante certo estágio de suas vidas; e ponderando, finalmente, que Tobias Barreto é um exemplo deste último, o que se buscou responder foi: - de que modo as medidas propostas por Tobias Barreto em sua experiência pública conformaram ou contradisseram suas posições teóricas? E ainda: - a sua experiência como político aportou alguma ideia nova à sua bagagem intelectual? E mais: Como Tobias Barreto explicou o fracasso da modernização do Brasil? - Ele a via como uma consequência, dada à inexperiência e o espirito absolutista de Dom Pedro II, ou a subordinação da mulher e a descriminação do homem escravizado, inclusive quando liberto?

Foi considerado que o oitocentos brasileiro, por uma série de aspectos se constituiu um divisor de águas em muitas esferas. Para além de todas as leis em defesa da liberdade, estava a discussão sobre o rompimento do regime de padroado e o que denominou Sylvio Romero de "surto das ideias novas" no Brasil, a exemplo do positivismo, do cientificismo, do ecletismo religioso e do darwinismo social. Em defesa dessas ideias, como revela Alonso (2002), muitos foram os homens que as alardearam e estas por sua vez, foram, a partir da necessidade brasileira e dos exemplos estrangeiros, a tônica para a mudança. O Brasil, nesse sentido, assim como vários outros países que tinham por incumbência a independência econômica e intelectual, buscou nos exemplos mais bem sucedidos, modelos políticos. Na analise de Tôrres (1973):

O interessante, porém, é que não haveria uma linha única, mas fontes inspiradoras diversas em política - o constitucionalismo francês, o parlamentarismo britânico, o federalismo americano, tendências comunistas ou fascistas de várias origens, em filosofia, o ecletismo, o positivismo, o spencerismo, o "germanismo" de Tobias Barreto, assim como diferentes modalidades modernas, bem conhecidas. (TÔRRES, 1973, p. 211).

O germanismo de Tobias Barreto, como uma "linha inspiradora", se revelou em diversas frentes da sua produção biobibliográfica e, nesse artigo, como enfatizado, o destaque foi para a educação feminina e a educação para o trabalho. Na condição de homem de ciência, Barreto adentrou a politica e, embora não reeleito, deixou contribuições significativas para se entender o império brasileiro pela ótica da história intelectual, pois suas ideias foram fruto de análises e interpretações do país, visto e concebido a partir do cotidiano do brasileiro, estivesse ele no topo ou na base da hierarquia econômica e cultural. Se se toma, por exemplo, as petições que ele impetrou na condição de advogado ou de curador geral dos orfãos é possível perceber o grau de conhecimento das demandas sociais de sua época. Casos de roubo, furto ou mesmo casos que envolviam herança, menores, loucos, mulheres, órfãos, fazem parte de seu repertório de defesas e que por certo faz da experiência profissional, aliada à observação, uma espécie de laboratório analítico. 
E se, por um lado, normalmente quando adentramos na história intelectual o que vemos são as ideias desprovidas dos seus mentores e, consequentemente, de suas angústias individuais, e, por outro, quando adentramos no estudo do campo político o que vem à tona é a formulação e/ou o cumprimento de legislações, o que se pôde perceber através do estudo das ideias, propostas e das práticas de Barreto foi que entre um e outro campo de estudo há um filão que deve ser computado na escrita da história e este é o da história do intelectual, pois os intelectuais tomam partido, se envolvem com politica, têm ideias, mas sobretudo expõem sua visão de mundo e de vida, no seu oficio de criticar, tesionar,mediar e propor soluções.

O que ficou claro ao abordar sua obra é que frente ao fracasso do Brasil rumo à modernização, ele propôs uma tríade em que o Direito aparece como um regulador social; a liberdade como fim da educação, compreendida também a feminina, o que supõe o ponto de partida da igualdade da mulher com o homem - e a educação como meio. Propôs, também, uma espécie de harmonização humboldtiana da cultura, em outras palavras, a cultura favorecendo um contexto a partir do qual pode ser pensada a emancipação social dos oprimidos e, consequentemente, o planejamento da modernização. A concepção de Tobias Barreto, mais do que partir da crítica a todos os membros da hierarquia social do Império, contempla a missão do homem de ciência para a qual, segundo Weber (1985), a visão de mundo permite apresentar padrões morais e eticos e a ciência se torna uma instância mediadora da vida. Por certo, organizar as contradições sociais e disseminar ideologias, como fazem os homens da política, também compôs seu capital cultural e talvez por isso, ao pensar a educação das mulheres e a educação para o trabalho, pensou a emancipação do brasileiro que, por sua vez, recaia na liberdade individual, no direito político, no bem-estar econômico e de segurança e, consequentemente, no direito de participar da herança social, pilar da cidadania.

\section{Referências}

ALONSO, Ângela. Ideias em movimento: a geração de 1870 na crise do Brasil Império. São Paulo: Paz e Terra, 2002.

BARRETO, Luiz Antônio. Tobias Barreto. Aracaju: Sociedade Editorial de Sergipe, 1994.

BARRETO, Raylane Andreza Dias Navarro. O moderno Tobias Barreto de Menezes no Brasil Império. In: BARRETO, Raylane Andreza Dias Navarro; MESQUITA, Ilka Miglio de; NOGUEIRA, Vera Lúcia (Orgs.). Moderno Modernidade Modernização: A educação nos projetos de Brasil. Belo Horizonte: Mazza Edições, v. 3, 2015.

BARRETO, Raylane Andreza Dias Navarro. Tobias Barreto e a Educação: ideias de um moderno no Império brasileiro. In: CARVALHO, Marcus Vinicius Corrêa; LAGES, Rita Cristina Lima; SILVA, Vera Lucia Gaspar da (Orgs.). Moderno Modernidade Modernização: A educação nos projetos de Brasil. Belo Horizonte: Mazza Edições, v. 4, 2016.

BARRETO, Tobias. Crítica de literatura e arte. Rio de Janeiro: Solomon; Editora Diário Oficial, 2012a.

. Estudos alemães. Rio de Janeiro: Solomon; Editora Diário Oficial, 2012b.

. Estudos de direito I. Rio de Janeiro: Solomon; Editora Diário Oficial, 2012c.

. Estudos de direito II. Rio de Janeiro: Solomon; Editora Diário Oficial, 2012d. 
. Estudos de direito III. Rio de Janeiro: Solomon; Editora Diário Oficial, 2012e.

. Estudos de filosofia. Rio de Janeiro: Solomon; Editora Diário Oficial, 2013.

. Monografias em Alemão. Rio de Janeiro: Record: Brasília: INL, 1990.

BOBBIO, Norberto. Os intelectuais e o poder. Dúvidas e opções dos homens de cultura na sociedade contemporânea. São Paulo: UNESP, 1997.

GOETHE. Fausto-Werther. São Paulo: Editora Nova Cultural, 2002.

NOVAES, Adauto (Org.). O Silêncio dos intelectuais. São Paulo: Cia das Letras, 2006.

PAIM. Antonio. Escola Eclética: Estudos complementares à história das idéias filosóficas no Brasil. V. IV. Londrina: Edições CEFIL,1999.

TÔRRES, João Camilo de Oliveira. Interpretação da Realidade Brasileira. Rio de Janeiro: Livraria Jose Olympio, 1973.

WEBER, Max. Ciência e política: duas vocações. São Paulo: Cultrix, 1985.

RAYLANE ANDREZA DIAS NAVARRO BARRETO é professora do Programa de Pós-Graduação em Educação da Universidade Tiradentes. Doutora em Educação pela Universidade Federal do Rio Grande do Norte, com estágio pós-doutoral na Universidade de Lisboa.

Endereço: Avenida Beira Mar, 1500 - Champs Elysée, ap. 904 - Bairro 13 de Julho - 49020-

010 - Aracaju/SE - Brasil.

E-mail: raylanenavarro@bol.com.br

Recebido em 20 de fevereiro de 2017.

Aceito em 22 de agosto de 2017. 